\title{
Synthesis of Silver Halide Nanosols
}

\author{
E. Michalak, P. Nowak, A. Król-Gracz and A. Dyonizy \\ Institute of Physical and Theoretical Chemistry, Wrocław University of Technology \\ Wybrzeże Wyspiańskiego 27, 50-370 Wrocław, Poland
}

\begin{abstract}
The aim of this work was to establish the average size of silver halide nanosols. The method applied was based on the optical turbidance measurements in real time of crystallization process. Dilute turbid suspensions of silver bromide, chloride and iodide stabilized by excess of halide ions and gelatin were measured over wavelength range from $450 \mathrm{~nm}$ to $600 \mathrm{~nm}$. Experimental results were compared with the scattering theory of Rayleigh. Relation between dosing rate of reactants to dispersion system and size of obtained silver halide crystals was investigated. Interest in crystalline gelatine-stabilised aqueous suspensions of silver halide is due to their application as a substrate for the synthesis of silver nanoparticles.
\end{abstract}

PACS: 81.07.-b

\section{Introduction}

Research into the synthesis of various average silver chloride, bromide and iodine crystals size in sols stabilized by hydrophobic polymers have been undertaken for many years [1-7]. The size of silver halide (AgHal) crystals are determined by turbidity measurements $[8,9]$ and electron microscope method. Similar studies on obtaining AgHal suspensions are conducted by our research group [10-13]. Developed methods for preparation of silver halide sols allow us to receive various size of crystals dependent on the concentration of reactants. Possibility of precipitation of $\mathrm{AgHal}$ suspensions using an established mechanism with reactants concentration in range $0.5-2.5 \mathrm{~mol} / \mathrm{l}$ has been investigated so far.

Depending on the type of silver halide and concentration of reactants various average size of crystals were obtained, for silver chloride from 70 to $200 \mathrm{~nm}$, silver bromide from 60 to $180 \mathrm{~nm}$ and silver iodide from 40 to $160 \mathrm{~nm}$, respectively [10-14]. Relatively large particles of AgHal obtained in the previously examined concentration of reactants did not satisfy the requirements for substrate used in the chemical reduction methods of silver nanoparticles preparation. This observation became the basis for the research into optimal conditions for synthesis of silver halide nanosols, with sizes below $30 \mathrm{~nm}$. The average size of silver halide crystals in these studies was established by turbidity measurements and scattering theory of Rayleigh [15].

Now, by using modern measurement techniques allowing for high speed acquisition of turbidity in the crystallization medium, there is possible direct and continuous control of the nucleation process, the Ostwald recrystallization and crystal growth of silver halide crystals. Simultaneous measurements of turbidity and activity of silver ions (or halogen ions) in the crystallization medium allow to control the preparation process of silver halide nanosols and the final sizes of crystals. The studies on using concentration of reactants $0.1 \mathrm{~mol} / \mathrm{l}$ have been a starting point for applications received suspensions of silver chloride, bromide and iodide crystals to produce silver nanosols. Interest in methods of preparation of silver nanoparticles by chemical reduction of crystalline suspensions of silver halides was an additional incentive to conduct research into AgHal nanosols (eg. [16, 17]).

\section{Experiments}

Precipitation of silver halide nanosols is based on producing thermodynamically stable crystal seeds of size not larger than $25 \mathrm{~nm}$. Processes of crystallization were prepared in water solutions of gelatin strongly impending silver halide crystals formation (Physical Retardance (PR), $\mathrm{PR} \approx 20-60$, PAGI method). $100 \mathrm{ml}$ of intensely stirred gelatin solution $(5 \mathrm{~g} / 100 \mathrm{ml})$ was introduced into alternately $10 \mathrm{ml}$ of silver nitrate solution and $10 \mathrm{ml}$ of alkali halide at $0.1 \mathrm{~mol} / \mathrm{l}$. The process of precipitation was ended after 10 cycles; a single cycle being the introduction of a single dose of silver nitrate solution and alkali halide solution each. The overall duration of precipitation did not exceed $300 \mathrm{~s}$. Final $300 \mathrm{ml}$ of silver halide crystals suspension was further stabilized by addition of gelatin in an amount ensuring its concentration as $5 \mathrm{~g} / 100 \mathrm{ml}$. Mechanism of precipitation of silver halide nanosols is described by Fig. 1 .

Earlier research into the influence of concentration and dosing rate of reactants upon the number and the average crystals size allowed us to characterize precipitation of silver halides sols at reactants concentration in range $0.1,0.5,1.0,1.5,2.0$, and $2.5 \mathrm{~mol} / 1$ [14]. These studies showed that silver halide crystals obtained at reactants concentration $0.1 \mathrm{~mol} / 1$ have the smallest size (Fig. 2) 


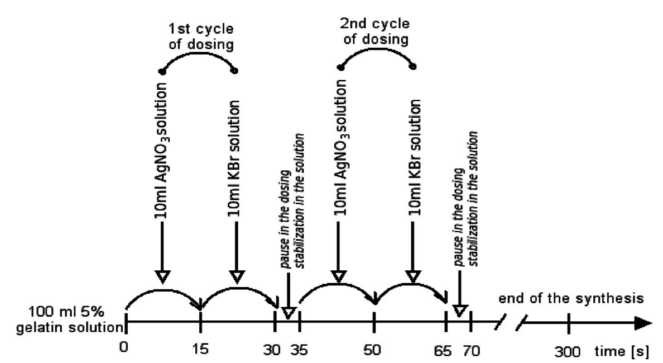

Fig. 1. Scheme of preparing of $\mathrm{AgBr}$ nanosols.

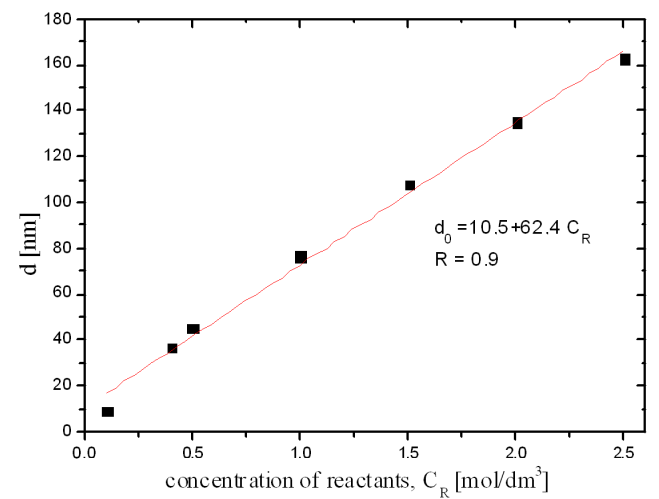

Fig. 2. Relation between the average size of silver iodide crystals approximated sphere and concentration of reactants used in the synthesis.

and can be applied to the synthesis of silver nanoparticles.

The measurements of turbidity in AgHal crystals suspensions were carried out by high speed acquisition (HSA). For this purpose, there were used USB4000-UV-VIS OceanOptics spectrometer and a transmission fiber probe with an optical length path of $10 \mathrm{~mm}$, which was placed directly in a reactor. Towards the end of the synthesis the suspensions were stabilized by addition of halogen ions to the value of pHal 2.5, 3.5 or 5.0 (for suspensions: $\mathrm{AgCl}, \mathrm{AgBr}$ and $\mathrm{AgI}$ ), and by addition of gelatin in an amount ensuring its concentration as $5 \mathrm{~g} / 100 \mathrm{ml}$. Afterwards the suspensions were cooled to form a permanent gel structure and washed out with cold, clean water to remove excess salts present in the gel.

\section{Results and discussion}

Fluctuation in turbidity as optical density during precipitation of silver halides nanosols, evaluated as a function of time of the synthesis can be seen in graphs (Figs. 3-5). In the initial stages of the synthesis thermodynamically unstable crystals seeds form, which under alternating, rapid changes in reagents concentrations, dissolve and reform alternately. A consistent increase in turbidity of crystallization mixture, systematically in each dosing cycle, up to the end of synthesis at cycle 10, proves the thesis about uniform growth of AgHal crystals.

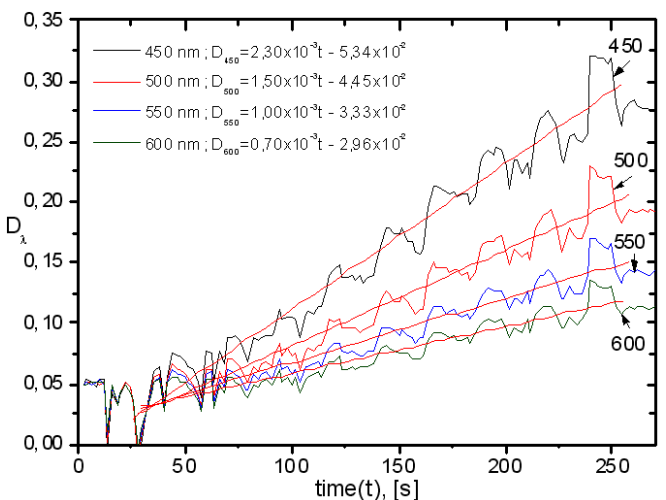

Fig. 3. Relation between turbidity as optical density of reactive mixture and duration of silver chloride nanosols synthesis, prepared using reacting substances solution at the concentration of $0.1 \mathrm{~mol} / \mathrm{l}$. Dependence was calculated at the wavelengths: 450, 500, 550, and $600 \mathrm{~nm}$.

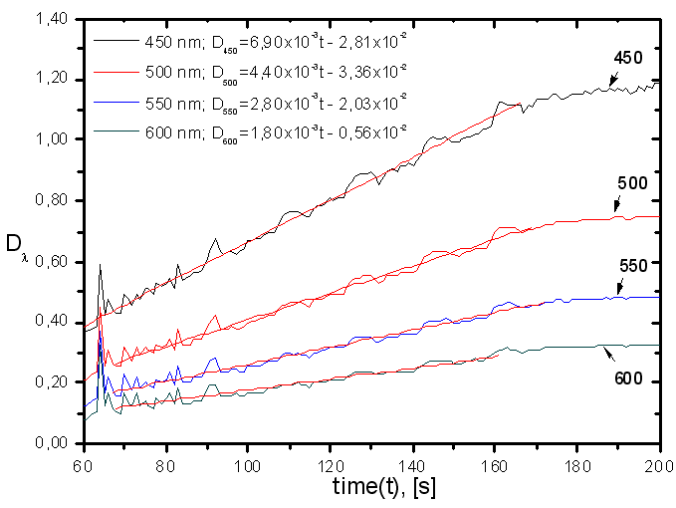

Fig. 4. Relation between turbidity as optical density of reactive mixture and duration of silver bromide nanosols synthesis, prepared using reacting substances solution at the concentration of $0.1 \mathrm{~mol} / \mathrm{l}$. Dependence was calculated at the wavelengths: $450,500,550$, and $600 \mathrm{~nm}$.

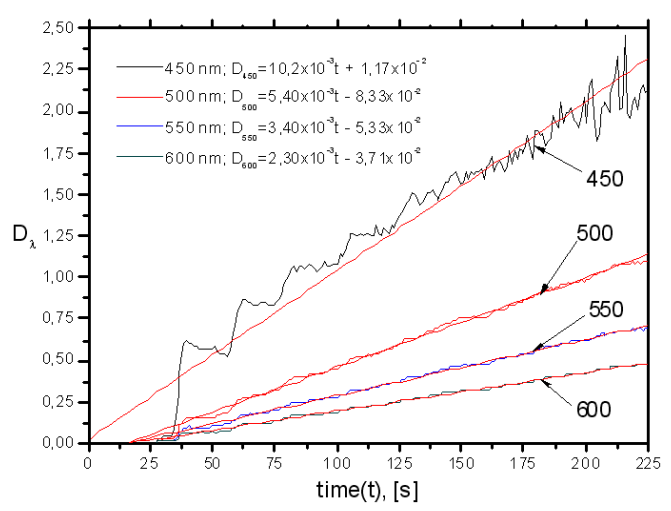

Fig. 5. Relation between turbidity as optical density of reactive mixture and duration of silver iodide nanosols synthesis, prepared using reacting substances solution at the concentration of $0.1 \mathrm{~mol} / \mathrm{l}$. Dependence was calculated at the wavelengths: $450,500,550$, and $600 \mathrm{~nm}$. 


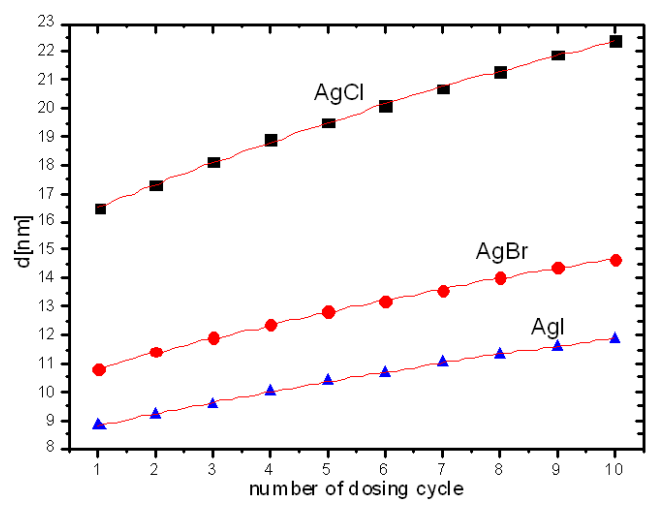

Fig. 6. Relation between size of silver halides spherical crystals and duration of nanosols synthesis, prepared using reactants solution at the concentration of $0.1 \mathrm{~mol} / \mathrm{l}$.

Fluctuation maxima of the turbidity function correspond to the exact moment of introducing a single dose of silver nitrate solution, while the function minima correspond to introduction of alkali halide solution. By addition of alkali halide into the crystallizing mixture, bromide ions concentration increases, which in turn increases the solubility of silver halide and smaller crystals dissolve. Consecutive introduction of silver nitrate solution dose, into the crystallizing mixture, results in appearance of a new, the thermodynamically unstable phase, able to recrystallise and deposit AgHal onto larger, stable crystals. The number of crystals thus increases, resulting in turbidity values. Due to the conditions of alternate reagents introduction each dosing cycle stabilises the size and number of crystals. Such conclusions are confirmed by the dependence of mixture turbidity and synthesis time, determined with good linear correlations, for four wavelengths 450, 500, 550, and $600 \mathrm{~nm}$ and plotted along with turbidity fluctuations in Figs. 3-5.

Based on the scattering theory of Rayleigh, which allows to determine the size of non-absorbing, spherical particles of AgHal, and measured turbidity of crystallization mixture new dependence was prepared, which is presented in Fig. 6. The smallest crystal size was calculated for the most difficult water-soluble silver iodide (AgI solubility is $9.74 \mathrm{mg} / 1$ at $25^{\circ} \mathrm{C}$ ). The diameter of AgI particles is of about $11 \mathrm{~nm}$, in the final stage of the synthesis. Silver bromide crystals $(\mathrm{AgBr}$ solubility is equal to $12.32 \mathrm{mg} / \mathrm{l}$ at $25^{\circ} \mathrm{C}$ ) after 10 cycles introduction of reagents are larger than silver iodide particles, and its size about $15 \mathrm{~nm}$. The size of $\mathrm{AgCl}$ nanocrystals is of $23 \mathrm{~nm}$ at the highest water solubility of described silver salts ( $\mathrm{AgCl}$ solubility is $16.08 \mathrm{mg} / \mathrm{l}$ at $25^{\circ} \mathrm{C}$ ).

\section{Conclusions}

The main aim of the research was to find optimal conditions for synthesis of silver halide nanosols containing the smallest size of particles. The method allows us to obtain crystals of chloride, bromide and silver iodide of size not exceeding $25 \mathrm{~nm}$. Particle size of AgHal allows their use as the substrate for the synthesis of silver nanoparticles, obtained by a slow, controlled chemical reduction. Applied measurement techniques and computational procedures, developed during the studies, give an opportunity to control the process of crystallization of chloride, bromide, and silver iodide nanosols and make a preliminary assessment of their usefulness in the further preparation of silver nanoparticles.

\section{Acknowledgments}

The study conducted under research project N507 601638 is financed from the Ministry of Science and Higher Education for 2010-2012.

When E. Michalak was doing her research, she received a grant co-funded by European Union as part of European Social Fund.

\section{References}

[1] B.H. Crawford, J. Sci. Instrum. 31, 333 (1954).

[2] C.R. Berry, D.C. Skillman, J. Phys. Chem. 68, 1138 (1964).

[3] H. Thiry, J. Photogr. Sci. 35, 150 (1987).

[4] H. Ohde, J.M. Rodriguez, X.-R. Ye, C.M. Wai, Chem. Commun. 23, 2353 (2000).

[5] M.M. Husein, E. Rodil, J.H. Vera, J. Nanoparticle Res. 9, 787 (2007).

[6] Y. Nimura, C. Mamiya, H. Masutomi, K. Ichikawa, U.S. Patent No. 5,605,790 (25 February 1997).

[7] K. Ohzeki, Y. Hosoya, J. Cryst. Growth 305, 192 (2007).

[8] E.J. Meehan, W.H. Beattie, J. Phys. Chem. 64, 1006 (1960).

[9] C.R. Berry, J. Opt. Soc. Am. 52, 888 (1962).

[10] A. Dyonizy, P. Nowak, A. Król-Gracz, E. Michalak, Patent Application No. PL389477 (5 November 2009).

[11] A. Dyonizy, P. Nowak, A. Król-Gracz, E. Michalak, Patent Application No. PL389476 (11 November 2009).

[12] A. Dyonizy, P. Nowak, A. Król-Gracz, E. Michalak, C. Mora, Patent Application No. PL394345 (28 March 2011).

[13] A. Dyonizy, P. Nowak, A. Król-Gracz, E. Michalak, C. Mora, Patent Application No. PL394449 (5 April 2011).

[14] A. Dyonizy, P. Nowak, A. Król-Gracz, E. Michalak, Chemik 64, 33 (2010).

[15] H.C. Van de Hulst, Light Scattering by Small Particles, Wiley, New York, 1957.

[16] J. Yang, H. Yin, J. Jia, Y. Wei, Langmuir 27, 5047 (2011).

[17] A.B. Moshe, G. Markovich, Chem. Mater. 23, 1239 (2011). 